\title{
PREDICTIVE FACTORS FOR PRIMARY AMPUTATION IN TRAUMA PATIENTS IN A NIGERIAN UNIVERSITY TEACHING HOSPITAL
}

\author{
O.O. ADEGBEHINGBE, A.L. AKINYOOLA and L.M. OGINNI
}

\begin{abstract}
Background: The decision to attempt salvage or to amputate a severely injured limb is among the most difficult decision that the orthopaedist must face.

Objective: To determine possible predictive factors that could become guides in taking decision for primary amputation as a first line treatment for trauma patients.

Design: A prospective study of post-traumatic primary limb amputations.

Setting: The Obafemi Awolowo University Teaching Hospital Ile-Ife, Nigeria from January, 2000 to December, 2004.

Subjects: Sixty six trauma patients admitted through the Accident and Emergency Unit from January 2000 to December 2004.

Results: Sixty six traumatised patient limbs were primarily amputated during the study period. The male: female ratio was 3.7:1 and means age was 28.6 years \pm 16.6 (range: $4-7$ years). $80.3 \%$ of the patients were below forty years. All the patients had a single limb amputation. The mean MESS score was $9.4 \pm 1.3$ (range: 7.0-12.0). The main predictive factors in trauma at the emergency unit for primary amputation include age, sex, occupation, limb ischaemia, gangrene, severe open fracture, source or nature of injury, presence of shock, delay in hospital presentation, and MESS.

Conclusion: Immediate amputation is often viewed by the patient and family as a result of the injury. Conversely, a delayed amputation may be viewed as a failure of treatment. Identified predictive factors for primary amputation will reduce trauma associated morbidity and mortality.
\end{abstract}

\section{INTRODUCTION}

Trauma remains a significant and persistent public health problem, accounting for 90,000 deaths and 20 million people disabled annually in United States of America. Furthermore, injury accounts for $12 \%$ of all medical spending and is the leading cause of death among young Americans aged one to 44 years (1). Major limb amputation represents a serious disability; this is compounded in the developing world by the difficulty in obtaining prostheses and the consequences of loss of earning ability, particularly if the patient is the only wage earner for a large extended family (2).
The outcome following injury is determined by time of injury to definitive care, quality of care, injury severity and host factors. It is generally accepted that injury severity is one of the most important factors in determining outcome after injury. Host factors are intrinsic to the patient and constitute physiological reserve. These factors encompass age, sex and the pre-injury medical state of the patient (3).

Sometimes, it is clearly not possible to be specific about the desirability of amputation in any particular pathological state including trauma as there are so many other factors to be considered. The age and occupation of the patient, his general 
physical state, social circumstances and habitat, the availability of prosthetic services among others may all influence the final decision. Nevertheless, some broad guidelines can be laid down. This study aimed at determining the predictive patient's characteristics for primary amputation in trauma.

\section{MATERIALS AND METHODS}

This was a hospital based prospective study at the Obafemi Awolowo University Teaching Hospitals Complex (OAUTHC), Ile- Ife, Nigeria. The subjects were trauma patients admitted through the Accident and Emergency unit from January 2000 to December 2004.

Protocols for each patient that required primary amputation were completed. These contain information on bioadata, hand dominance, source of injury, time interval from injury to hospital presentation, clinical signs at first contact, soft tissue/skeletal injuries, complications (gangrene, tetanus, septicaemia, shock), Mangled Extremity Severity Score (MESS) (4) and level of amputation. The MESS is a scheme devised to give a quantitative assessment of the severity of injury to a limb, and to offer a guide in making the difficult decision as to whether it is worth striving to save the limb or to minimise losses and advise a primary amputation. In applying the MESS, four factors are considered and the scores for each were added together to obtain a total (range: 2-14). A score of 7.0 or more is considered a highly reliable guide to the need for amputation. However, a score of less than 7.0 does not necessarily guarantee that amputation may not eventually be required. All patients were evaluated by a Senior Registrar and a Consultant traumatologist before decision for amputation was taken. All trauma patients had access to a functioning CT scan, Doppler ultrasound and angiography for vascular evaluation. Patients with known metabolic disorders and peripheral vascular diseases were excluded.

The levels of statistical significance using chisquare or student's T-test were all determined at $\mathrm{p}<0.05$. The Statistical Package for Social Sciences (SPSS) version 11.0 computer software was used to analyse the data.

\section{RESULTS}

A total of 3,812 trauma patients were attended to at the accident and emergency units of the OAUTHC, Ile-Ife, during the study period. Sixty six (1.73\%) patients required primary amputation due to the injuries sustained. There were 52 (78.8\%) males and $14(21.2 \%)$ females, a male to female ratio of 3.7:1.0. The mean age was 28.6 years \pm 16.6 (range: $4-71$ years). The patients below forty years were 53(80.3\%). The association between age, sex and primary amputation was significant $(p<0.05)$. An annual rate of 13.2 was recorded and twenty nine (43.9\%) limbs that developed gangrene as a complication of traditional bone setter's treatment were seen.

Figure 1 shows the age group distribution for amputation. The duration of trauma at hospital presentation was more than six hours in $47(71.2 \%)$ patients and $19(28.8 \%)$ cases were seen in less than six hours. There was no limb that was simply cold paralysed insensate after 72 hours of trauma injury.

Figure 1

Age distribution of patients

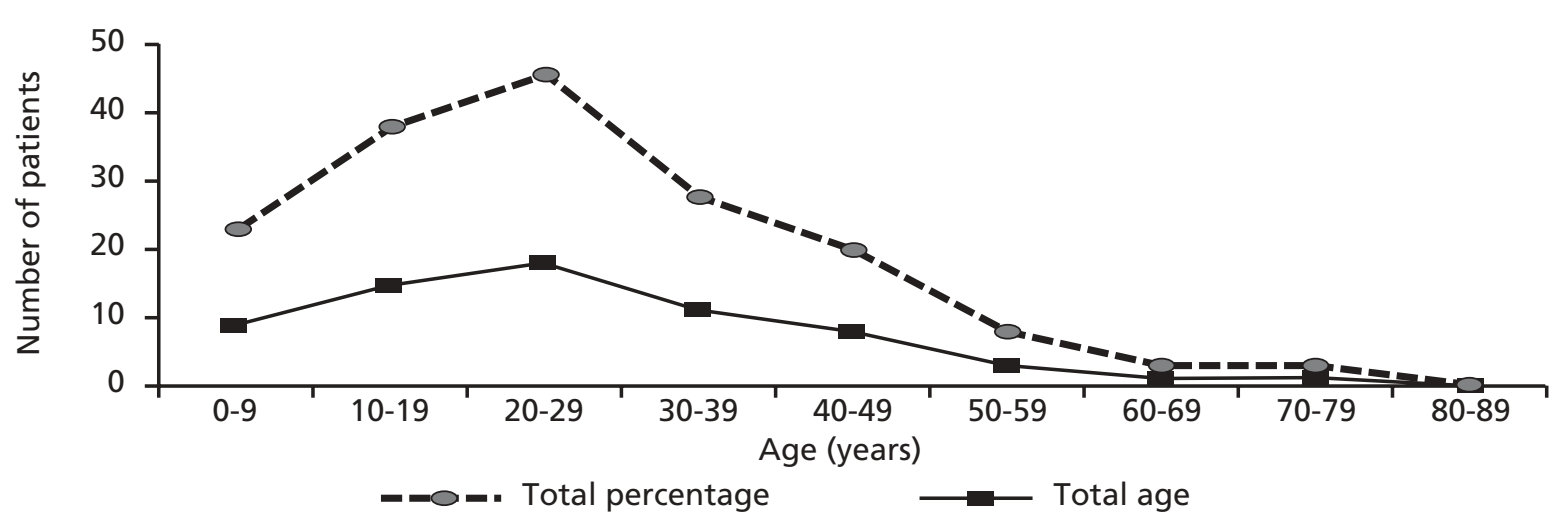


Table 1 shows occupation distribution with 58 $(87.9 \%)$ of the patients engaged in education, trading and farming. Table 2 shows the causes of trauma. Seven patients had other complications at presentation. These included gas two with gangrene, three with tetanus and two with septicaemia. Fifty six $(84.8 \%)$, eight $(12.1 \%)$, and two $(3.0 \%)$ patients presented with normal blood pressure, transient and persistent hypotension respectively. Fifty two $(78.8 \%)$ patients were with open wound and 14 (21.2\%) had simple fractures (Table 3). The MESS score ranged from 7.0-12.0 (mean: $9.4 \pm 1.3$ ) (Figure 2). Primary amputation of the upper limb was done in 23 patients (34.8\%; left: 9; right: 14) and lower limb amputation in 43 patients (65.2\%; left: 18; right: 25$)$. The level of amputation show that $13(19.7 \%)$ were below elbow and $10(15.2 \%)$ were above. Also, 24 (36.4\%) above and $19(28.8 \%)$ below knee primary amputations were recorded. Seven patients died, with mean age 39.7 years \pm 18.1 (male 5 ; female 2 ) and their mean MESS was $9.8 \pm 1.4$. Six $(85.7 \%)$ and one patient $(14.3 \%)$ of the mortality were from road traffic accident and gunshot respectively.

Table 1

Occupational distribution of patients

\begin{tabular}{lcc}
\hline Occupation & No. of patients & $(\%)$ \\
\hline Schooling & 26 & 39.4 \\
Artisan (Labourers, mechanic, hair dressing) & 12 & 18.2 \\
Trading & 10 & 15.2 \\
Lumbering & 7 & 10.6 \\
Farming & 3 & 4.6 \\
Teaching & 2 & 3.0 \\
House wife & 2 & 3.0 \\
Driving & 2 & 3.0 \\
Clergyman & 1 & 1.5 \\
Nursing & 1 & 1.5 \\
\hline Total & 66 & 100 \\
\hline
\end{tabular}

Table 2

Causes of trauma in primary amputation

\begin{tabular}{lcc}
\hline Source of trauma & No. of patients & $(\%)$ \\
\hline Road traffic accident & 27.0 & 40.9 \\
Industrial accident & 19.0 & 28.8 \\
Gunshot injury & 8.0 & 12.1 \\
Domestic accident & 5.0 & 7.6 \\
Fall from height & 4.0 & 6.1 \\
Hunting & 2.0 & 3.0 \\
Blast injury & 1.0 & 1.5 \\
\hline Total & 66 & 100 \\
\hline
\end{tabular}


Table 3

Soft tissue injury in primary amputation

\begin{tabular}{lcc}
\hline Soft tissue injury & No. of patients & $(\%)$ \\
\hline Crush injury + Gross contamination & 27 & 40.9 \\
Open fracture - Gustilo Type I & 10 & 15.2 \\
- Gustilo Type II & 1 & 1.5 \\
Simple fracture & 14 & 21.2 \\
Traumatic amputation & 9 & 13.6 \\
Mangled limb & 4 & 6.1 \\
Stab wound + gross contamination & 1 & 1.5 \\
\hline Total & 66 & 100 \\
\hline
\end{tabular}

Figure 2

Mess in traumatic primary amputation

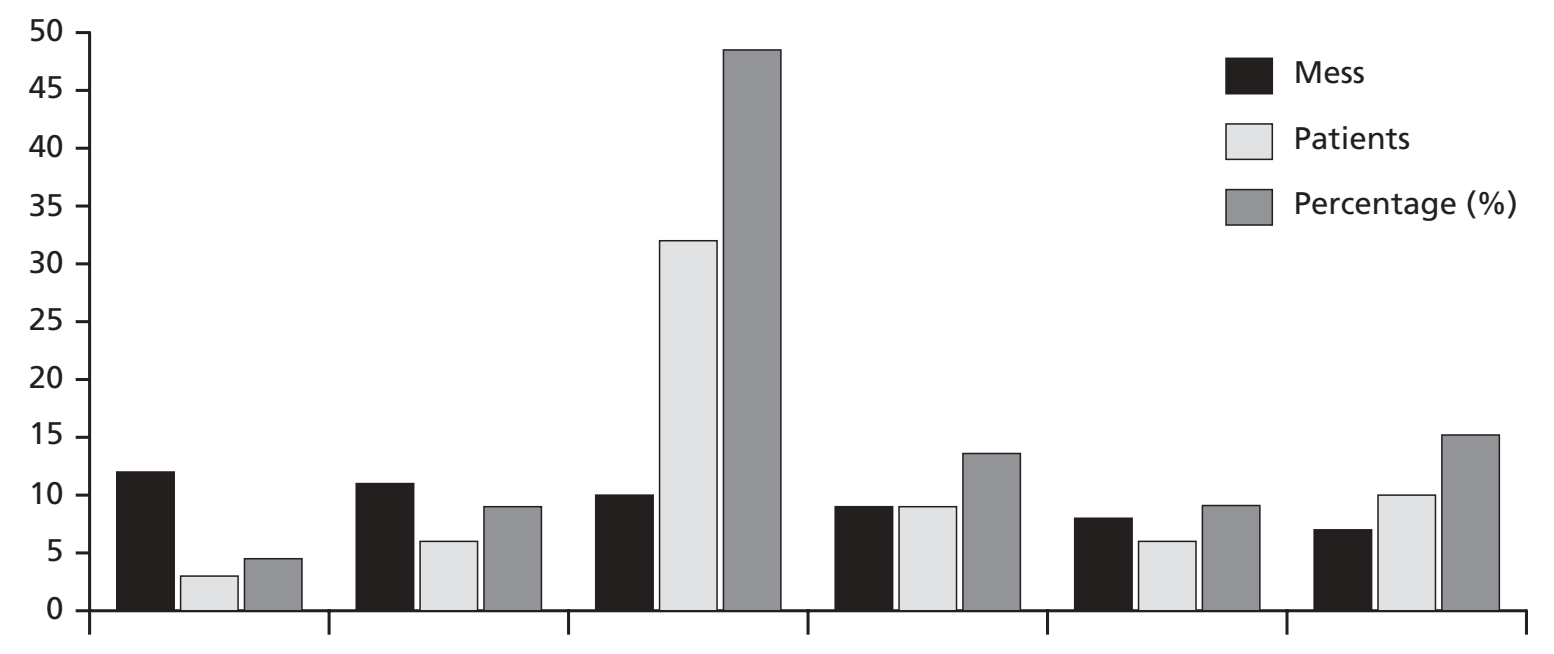

DISCUSSION

Amputation of a mangled extremity is repugnant to the patient and the surgeon. However, prolonged unsuccessful attempts at salvage are costly, highly morbid, and sometimes lethal. The Mangled Extremity Severity Score (MESS) system is the most thoroughly validated of the various classification systems, but at present there is no predictive scale that can be used with confidence to determine whether to amputate or attempt to salvage a mangled lower extremity (5). Limb salvage decisionmaking variables were summarised into thirteen broad categories (6). In extreme cases using the criteria of prolonged ischaemia (longer than six hours) and or absent posterior tibia nerve function are absolute indications for amputation (7).
Unfortunately, it is not only the limb that is lost with delayed amputation. Many patients, as a result of this protracted experience, are destroyed physically, psychologically, socially and financially $(8,9)$.

Trauma patients under 40 years are more likely to end up with primary amputation than those in the older age group because they are more involved in road traffic accidents, extreme work-related injuries such as lumbering, blast and gunshot injuries. Children are exposed to the same home related /industrial mishaps especially grinding and flour rolling mill belt injuries resulting in severely crushed devitalised limbs. The male sex is known to take risks. This commonly exposes them to severe trauma at home and on the road compared with the female gender. Consequently, this predisposes them to have higher risk of primary amputation. 
Traumatised patients without gender bias that present late beyond six hours with the limb ischaemia do have a higher risk for primary amputation than those patients with traumatic injuries who for individualised cases. The reasons for the delay in presentation are linked to inadequate means of transportation from the site of trauma, insufficient and inappropriate first aid treatment, ignorance, poverty and diversionary visit to the traditional bone setters.

The source of trauma is equally unique in determination of trauma patients that will have primary amputation. Injuries sustained from road traffic accident, industrial accident, and gunshot injuries are at a higher risk of primary amputation than those from trauma sustained through fall from height (palm tree, kola nut tree, and construction buildings), minor domestic injuries and sport events. This is because the injuries acquired from these aforementioned sources are often severely crushed, devitalised, grossly contaminated and complications are more often than ever with severe infection of the wounds and almost irreparable vascular damage. There is a significant trauma-related amputation in injuries involving machinery, powered tools and appliances, fire arms and motor vehicle crashes (10). Trauma patients from road traffic accident with compromise of the peripheral blood supply were understandably the most common victims of amputation (11). In the young age group, among whom the majority of these injuries occurred, rapid rehabilitation and return to a functional life is usually possible with primary amputation (12). The chances for rapid rehabilitation and recovery from injury for patients who have multiple procedures and prolonged hospitalisation are poorer than the chances for those who have primary amputation $(9,13)$.

The patients at presentation assessed to have persistent hypotension as a sequel of their injury have a preponderance of high risk for primary amputation than those with normal blood pressure or transient hypotension. All haemodynamically shocked patients existing beyond six hours ended with amputation. The simple fractures, and Gustilo type I and II open fractures were seen with traditional bone setter's gangrene. Also, gas gangrene, clinical tetanus and uncontrollable septicaemia increase the risk for amputation primarily. Mangled limbs and crushed extremity have high predictive risk for primary amputation in trauma (14-18)

The Mangled Extremity Severity Score is a simple rating scale based on skeletal / soft-tissue damage, limb ischaemia, shock, and age. A MESS value greater than or equal to 7.0 predicted primary amputation with $100 \%$ accuracy in this study. However, MESS underscores some of the trauma patients especially those that presented late to the hospital post-injury with complications. This aspect will be further evaluated in the next study. MESS is a useful predictive factor for selecting trauma patients with irretrievably injured limb extremities suitable for primary amputation. As found here, MESS score of $\geq 7.0$ had a $100 \%$ predictable value for amputation (5).

\section{CONCLUSION}

Advances in medicine and surgery have allowed for dramatic improvements in the management of limb extremities injury. Some salvage attempts have led patients to have repeated hospitalisations, extensive complications and a poor functional outcome. The ultimate decision to amputate or attempt salvage is based on such patient factors as pre-injury function and social situation and of associated injuries, surgeon experience, available resources, projected physical abilities, and the patient's projected physical requirements. These decisions are difficult and tax the judgment and emotions of the patient, family, and physician.

The main predictive factors for primary amputation in trauma are patient's age, sex, skeletal/soft tissue injuries, limb ischaemia and gangrene. Other factors are the presence of shock, delay in presentation, and mangled extremity severity score.

\section{REFERENCES}

1. Cornwell E.E. Current concepts of gunshot wound treatment. A trauma surgeon's perspective. Clin. Orthop. E Related Res. 2003; 408: 58-64.

2. Jaiyesmi F. Peripheral gangrene in childhood : Further observations on its etiology and psychological sequelae in Nigeria. Trop. Geograph. Med. 1977; 29: 159-164.

3. Vander Sluis C.K., Trimmer H.W., Eisma W.H. and Duis H.J. Outcome in elderly injured patients : Injury severity versus host factors. Injury. 1997; 28: 588-592. 
4. Helfet D.L., Howey T., Sanders R. and Johansen K. Limb salvage versus amputation. J. Clin. Orthop. $\mathcal{E}$ Related Res. 1990; 256: 80-86.

5. Akoz T., Yildirim S., Akan M., et al. Can indications for lower limb replantation and revascularisation be expanded with simultaneous free-flap transfer for limb salvage? J. Reconstruct. Microsurg. 2004; 20: 621-629.

6. Battiston B., Tos P., Pontini I. and Ferrero S. Lower limb replantations: Indications and a new scoring system. Microsurg. 2002; 22: 187-192.

7. Dirschl D.R. and Dahners I.E. The mangled extremity: When should it be amputated? J. Amer. Acad. Orthop. Surg. 1996; 4: 182-190.

8. Lange R.H. Limb reconstruction versus amputation decision making in massive lower extremity trauma. Clin. Orthop. 1989; 234: 92.

9. Lange R.H., Bach A.L., Hansen S.T. and Johansen K. Open tibial fractures with associated vascular injuries: Prognosis for limb salvage. J. Trauma. 1985; 25: 203-208.

10. Hansen S.T. Jr. Overview of the severely traumatised lower limb: Reconstruction versus amputation. Clin. Orthop. 1989; 243: 17.

11. Moore T.J., Green S.A. and Garland D.E. Severe trauma to the lower extremity long-term sequelae. South Med. J. 1987; 82: 843.

12. Asogwa S.E. Epidemiology of road traffic accident in
Nigeria in Sofoluwe G.O., Bennett F.J. (Eds): Principles and practice of community health in Africa. University Press Ltd, Ibadan. 1985; 557-573.

13. Lambert C.N., Hamilton R.C. and Tellicore R.J. The juvenile amputation program: It's social and economic value. A follow-up study after the age of twenty one. J. Bone E Joint Surg. 1969; 51A: 1135.

14. Boundurant F., Colter H.B., Buckle R., et al. The medical and economic impact of severely injured lower extremities. J. Trauma. 1988; 28: 1270.

15. Dillingham T.R., Pezzin L.E. and MacKenzie E.J. Incidence, acute care, length of stay and discharge to rehabilitation of traumatic amputate patients: An epidemiologic study. Arch. Phys. Med. E Rehabil. 1998; 79: 279-287.

16. Seekamp A., Regel G., Ruffert S., et al. Amputation or reconstruction of III B and open tibial fracture. Decision criteria in the acute phase and late functional outcome. Unfallchirug. 1998; 101: 360-369.

17 Kidmas A.T., Nwadiaro C.H. and Igun G.O. Lower limb amputation in Jos, Nigeria. East Afr. Med. J. 2004; 81: 427-429.

18 Ghali S., Harris P.A., Khan U., et al. Leg length preservation with pedicle fillet of foot flaps after traumatic amputations. Plast. Reconstr. Surg. 2005; 115: 498-505. 